\title{
CELLULOSE NANOFIBRILS MODIFICATION WITH POLYANILINE AIMING AT ENHANCING ELECTRICAL PROPERTIES FOR APPLICATION IN FLEXIBLE ELECTRONICS
}

\author{
LUIZ EDUARDO SILVA, ${ }^{*}$ PEDRO IVO CUNHA CLARO, ${ }^{* *}$ \\ RAFAELA CRISTINA SANFELICE, ${ }^{* * *}$ MÁRIO GUIMARÃES JÚNIOR, ${ }^{* * * *}$ JULIANO ELVIS DE \\ OLIVEIRA, , JÚLIO CÉSAR UGUCIONI, DANIEL SOUZA CORREA ${ }^{* * * * *}$ and \\ GUSTAVO HENRIQUE DENZIN TONOLI* \\ "Federal University of Lavras, P.O. Box 3037, 37200-000, Lavras, MG, Brazil \\ ${ }^{* * *}$ Federal University of São Carlos, SP 13565-905, São Carlos, Brazil \\ ${ }^{* * *}$ Institute of Technological and Exact Sciences, Federal University of Triângulo Mineiro, \\ 38064-200, Uberaba, MG, Brazil \\ ${ }^{* * * * *}$ Federal Center for Technological Education of Minas Gerais, 25, Ministro Olavo Drummond Av., \\ 38180-510, Araxa, MG, Brazil \\ ${ }^{* * * * *}$ Nanotechnology National Laboratory for Agriculture, Embrapa Instrumentação, Rua XV de Novembro \\ 1452, Centro, 13560-970, São Carlos, SP, Brazil \\ \Corresponding author: L. E. Silva, lesilvaflorestal@gmail.com
}

Received March 19, 2019

\begin{abstract}
This work aims to produce, characterize and compare the properties of composite films of cellulose nanofibrils (CNF) and polyaniline (PANI) doped with two distinct acids. CNF were produced by mechanical fibrillation and combined with PANI via in situ polymerization. The results revealed that PANI presented successful polymerization and homogenous dispersion throughout the films with no distinctive separation from cellulose. The films containing PANI doped with $\mathrm{HCl} 1 \mathrm{M}$ and $2 \mathrm{M}$ presented significantly higher values in comparison with the films produced with only CNF. The charge transfer resistance evaluated by impedance spectroscopy for the films with PANI was lower than for the CNF films, indicating an improvement in electrical conduction, which in turn helped increasing charge storage. Even though the films of PANI doped with citric acid showed lower values compared to those of the films doped with $\mathrm{HCl}$, citric acid is a suitable and greener dopant and therefore, it is worth being further investigated for conducting thin films containing cellulose for application in green electronics.
\end{abstract}

Keywords: conducting nanocomposites, electrochemical impedance spectroscopy, parallel plate capacitance, citric acid, hydrochloric acid

\section{INTRODUCTION}

In recent years, organic-based electronic devices have gained importance in traditional electronics industry, due to their technological, environmental and economic advantages. Cellulose is a renewable, biodegradable, inexpensive and insulating material ${ }^{1}$ displaying dielectric properties. ${ }^{2,3}$ Cellulose presents a dielectric constant lower than 5, but this value can be increased two to three-fold when at the nanoscale, due to its densification. ${ }^{4-6}$ Additionally, it has a breakdown strength of approximately 600 $\mathrm{kV} . \mathrm{cm}^{-1}$, which is one order of magnitude lower than that of polymer-based dielectric materials, due to the hydroxyl groups lying on its surface. ${ }^{6}$

Polyaniline (PANI) is a conjugated polymer of easy manipulation and can be polymerized upon cellulose. $^{7-10}$ It is generally doped in order to considerably increase its electrical conductivity, improving its conductivity and capacitance. ${ }^{11-13}$ PANI can be found in three states of oxidation: leucoemeraldine, pernigraniline, emeraldine. While leucoemeraldine and pernigraniline base are commonly insulating, the emeraldine form is found naturally as conductive. ${ }^{12}$ PANI's 
emeraldine base form is achieved by partial oxidation, and it generates protonated emeraldine salt after doping with protonic acid. ${ }^{11,14}$

Many properties of PANI, including solubility, crystallinity and interplanar distance, depend on the type and size of the dopant used. ${ }^{12}$ Strong acids, as hydrochloric acid $(\mathrm{HCl})$, are most indicated for increasing the conductivity of PANI. ${ }^{15}$ However, there is not a single acid capable of producing all of its properties of excellence, such as conductivity and processability. ${ }^{12}$ Citric acid is a non-corrosive dopant that can be used with polysaccharides of vegetable fibers, being capable of cross-linking the cellulose chains, ${ }^{16}$ increasing the dimensional stability of the cellulose-based films, which is one of the major problems in the production of cellulose-based electronic components. ${ }^{17}$

In situ polymerization is a practical and easy method for deposition of PANI on several substrates, once it does not require the use of polar or metallic support as in electrochemical polymerization. ${ }^{14,18,19}$ Such features make in situ polymerization very attractive for the modification of cellulosic components; for instance, it has been applied in the production of supercapacitors, ${ }^{20-23}$ in association with nylon fibers, ${ }^{24}$ carbon nanotubes, ${ }^{25,26}$ silver nanoparticles, ${ }^{27,28}$ PANI conductive films ${ }^{28,29}$ and even for drug removal in aqueous media. ${ }^{30}$

The combination of PANI with cellulose nanofibrils $(\mathrm{CNF})$ can result in a composite with high mechanical strength, due to the high tensile strength of $\mathrm{CNF}^{6,31}$ which can also enhance the capacitance of the nanocomposite, since both polymers display dielectric features., ${ }^{2,6,13,22}$ Although some studies have reported PANI and cellulose composites, in most cases, a strong acid was used as doping agent ${ }^{22,25,30,32}$ or electromagnetic radiation. ${ }^{33}$ Citric acid has rarely been used as an effective doping acid in PANI, ${ }^{34}$ and the capacitance of films with citric acid has not been assessed yet. In this context, here we evaluated the mild acidity effect promoted by citric acid (as an alternative for $\mathrm{HCl}$ ) as dopant for in situ polymerized CNF-PANI composite films and investigated the changes on the physicochemical and electrical properties of the resultant nanostructured films.

\section{EXPERIMENTAL Materials}

Commercial Kraft pulp of Eucalyptus sp. from CENIBRA S.A. was used as starting material to obtain
CNF suspension. Pulp fibers presented an average fiber length of $0.81 \pm 0.01 \mathrm{~mm}$ and an average diameter of $15.9 \pm 0.3 \mu \mathrm{m}$. The pulp was composed of cellulose (86.3\%), hemicelluloses (12.9\%) and extractives and ashes $(0.8 \%) \mathrm{HCl}(37 \%$ purity) and citric acid (99.5\% purity) were purchased from Quimex and Vetec, respectively. Ammonium persulfate (APS) was obtained from Sigma Aldrich. Aniline was purchased from Neon and double-distilled at the laboratory.

\section{Production of CNF}

The mechanical fibrillation of the cellulose fibers was based on the work of Guimarães et $a l .{ }^{35}$ and Bufalino et al. $^{36}$ For fibrillation, the pulp was immersed in distilled water for three days, mixing the dispersion each day, to completely soak the fibers. The final concentration was $1 \%(\mathrm{w} / \mathrm{w})$. Then, the suspension was submitted to the SuperMasscolloider Masuko Sangyo grinder (MKCA6-3; Masuko Sangyo Co., Ltd.), with 30 passes through the grinder at 1500 rpm, with energy consumption of $1.0 \times 104 \mathrm{kWh} /$ ton of fibers. The stones were close enough to individualize the fibers, but not exceeding $6 \mathrm{~A}$ in current not to overuse the equipment.

\section{Preparation of the films}

The polymerization methodology of PANI was based on the work of Silva et al. ${ }^{37}$ Initially, $200 \mathrm{~mL}$ of CNF suspension was mixed with acid (hydrochloric or citric) under controlled temperature $\left(4^{\circ} \mathrm{C}\right)$ for $50 \mathrm{~min}$. Subsequently, $100 \mathrm{~mL}$ of aniline was added and stirred for another $10 \mathrm{~min}$. Finally, a solution containing 58 $\mathrm{mg}$ of APS in $10 \mathrm{~mL}$ of the corresponding acid were added, dropwise. After addition of all the reagents, the dispersion was stirred for $4 \mathrm{~h}$ and stored under refrigeration for $12 \mathrm{~h}$ to complete the synthesis. The formation of the films followed the procedure according to Razaq et al., ${ }^{32}$ using a Buchner funnel to vacuum filter and then the film was pressed and ovendried overnight at $50{ }^{\circ} \mathrm{C}$. The suspension filtering helps in film formation, draining the excess water and reducing oven time. A scheme of the CNF/PANI films is displayed in Figure 1.

A total of nine distinct films were produced, one being made with only CNF (control) and eight films using CNF, PANI and a protonating acid (hydrochloric or citric) in varying concentration (Table 1). For the nomenclature of the films, a letter was used (with the exception of the CNF film) for identifying the films when doped with hydrochloric acid $(\mathrm{H})$ or citric acid (C); and numbers ranging from 0.1 to 2.0 to symbolize the acid concentrations.

\section{Characterization of the films}

The cast films obtained from the different solutions described in Table 1 were characterized by field emission gun scanning electron microscopy (FESEM), Fourier transform infrared spectroscopy with 
attenuated total reflectance (FTIR-ATR), color analysis, parallel plate capacitance and electrochemical impedance spectroscopy (EIS).

\section{Field emission gun scanning electron microscopy}

Images of the fracture surface of the films were obtained using a FE-SEM microscope, model JSM-
$6701 \mathrm{~F}\left(\mathrm{JEOL}^{\circledR}\right)$, using a $4 \mathrm{kV}$ acceleration voltage. The samples were fixed on aluminum stubs, using carbon tape, with no coating. The images were obtained from the cross-section plane created by a cryogenic fracture.
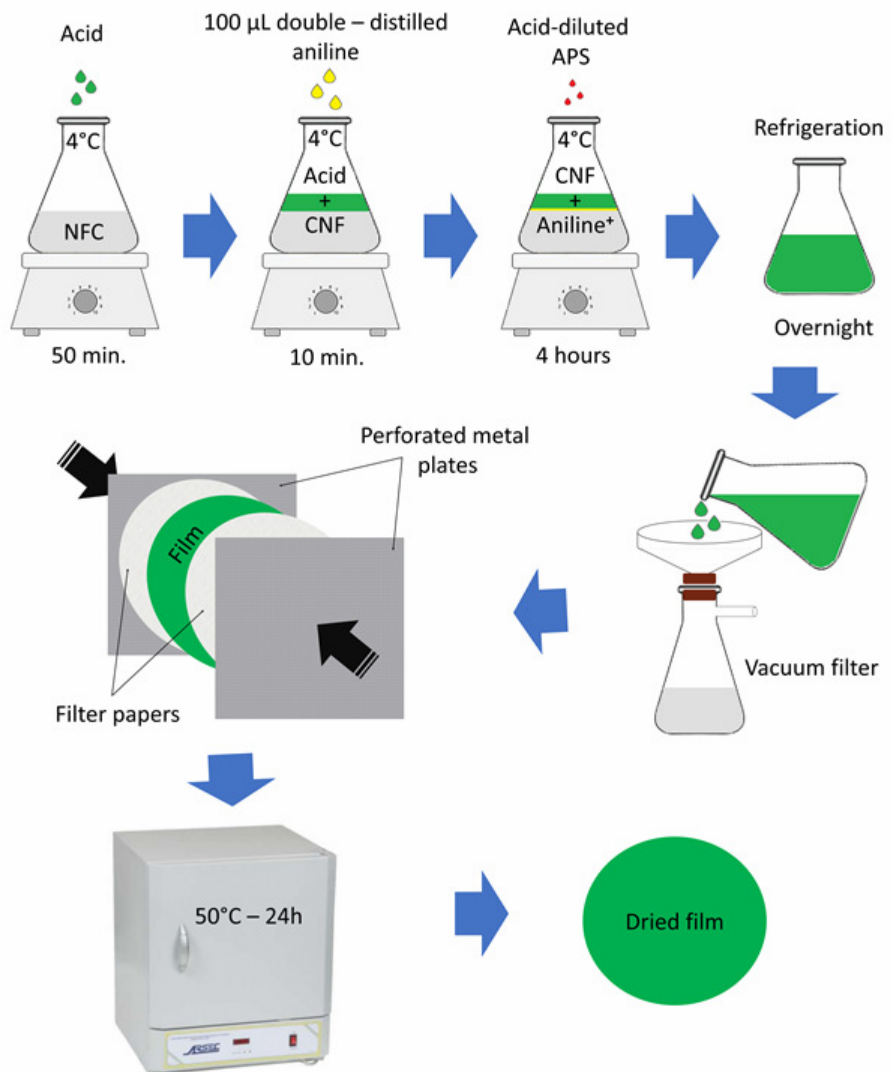

Figure 1: Scheme for cellulose/PANI cast film formation (for each treatment, the acid and its concentration were set according to Table 1; other parameters, as aniline and APS concentration, were the same for all the treatments; films containing only CNF were vacuum filtered and oven-dried)

Table 1

List and coding of the different cellulose/PANI films

\begin{tabular}{lccc}
\hline Components & & Code & Concentration \\
\hline & & $\mathrm{H} 0.1$ & $0.1 \mathrm{M}$ \\
& Hydrochloric acid & $\mathrm{H} 0.5$ & $0.5 \mathrm{M}$ \\
Cellulose & $\mathrm{H} 1.0$ & $1.0 \mathrm{M}$ \\
nanofibrils and & $\mathrm{H} 2.0$ & $2.0 \mathrm{M}$ \\
\cline { 2 - 4 } PANI doped with & & $\mathrm{C} 0.1$ & $0.1 \mathrm{M}$ \\
& \multirow{2}{*}{ Citric acid } & $\mathrm{C} 0.5$ & $0.5 \mathrm{M}$ \\
& & $\mathrm{C} 1.0$ & $1.0 \mathrm{M}$ \\
& & $\mathrm{C} 2.0$ & $2.0 \mathrm{M}$ \\
\hline Cellulose nanofibrils & $\mathrm{CNF}$ & - \\
\hline
\end{tabular}




\section{LUIZ EDUARDO SILVA et al.}

\section{Fourier transform infrared spectroscopy with attenuated total reflectance \\ FTIR-ATR spectra were obtained in a Varian FTIR} 660 spectrometer with attenuated total reflectance coupled apparatus (ATR, Pike Technologies), with one reflection diamond slit. The spectra acquisition was obtained in the range from 4000 to $400 \mathrm{~cm}^{-1}$, operating in the absorbance mode with $4 \mathrm{~cm}^{-1}$ resolution and performing 16 scans per sample. To eliminate coarse noise in the signal, it was subsequently subjected to a filter by the adjacent average technique with 20 points per window. For comparison and better visualization of the vibration derived from the benzoic and quinoid rings present in PANI molecules, control samples containing PANI with $\mathrm{HCl}$ (HC) and citric acid (CC), without the presence of $\mathrm{CNF}$ were produced. The films were kept under room conditions to balance their water contents with air humidity.

\section{Color analysis}

Colorimetric analysis of $\mathrm{CNF}$ and PANI films was performed in a spectrophotometer (Konica Minolta ${ }^{\circledR}$, CM-5, Osaka, Japan), at a visual angle of $10^{\circ}$ and illuminant D65 (daylight), according to Hunterlab. ${ }^{38}$ Six readings were performed for each treatment. The parameters $\mathrm{L}^{*}, \mathrm{a}^{*}$ and $\mathrm{b}^{*}$ are axes in a plane according to the opposite color theory, ${ }^{38}$ where $\mathrm{L}^{*}$ (lightness) represents the light intensity reflected by the sample, while the parameters $a^{*}$ and $b^{*}$ represent the red-green and blue-yellow axes, respectively. The color difference between the samples and the standard $\left(\Delta \mathrm{L}^{*}\right.$, $\Delta \mathrm{a}^{*}$ and $\left.\Delta \mathrm{b}^{*}\right)$ was determined for the calculation of the total color difference $\left(\Delta \mathrm{E}^{*}\right)$, in which the standard has the following parameters: $L^{*}=97.52, a=-0.24$ and $b$ $=0.36$. The total color difference $(\Delta \mathrm{E})$ was calculated according to Equation (1). The means of the values were compared using Tukey's test at 5\% significance.

$$
\Delta E^{*}=\sqrt{\Delta a^{*^{2}}+\Delta b^{*^{2}}+\Delta L^{*^{2}}}
$$

\section{Parallel plate capacitance}

For measuring the capacitance of the films, the parallel plate method ${ }^{39}$ was used. The apparatus consists of two circular shaped metal plates with a nominal area of $26.4 \mathrm{~cm}^{2}$ and pressed with pressure clips, as shown in Figure 2. The plates were connected to an ICEL Manaus CD-300 multimeter operating at a frequency of $8-800 \mathrm{~Hz}$, varying with the selected scale, which ranges from $1.0 \pm 0.1 \mathrm{pF}$ up to $20000 \pm 10 \mu \mathrm{F}$.

By the results of the capacitance measurements, it is possible to define the dielectric constant $(\mathrm{k})$ of the films with Equation (2):

$$
k=\frac{C}{\left(\frac{\varepsilon_{0} * A}{d}\right)}
$$

where $\mathrm{C}$ is the capacitance measured by the multimeter (in Farads), $\varepsilon_{0}$ is vacuum permittivity $\left(8.85 \times 10^{-12}\right)$, A is the area of the metal plates, and $d$ is the distance between the plates (considered as the film thickness).

Measurements were performed at room temperature and humidity and on dry films as well. The films were dried at $50{ }^{\circ} \mathrm{C}$ for $24 \mathrm{~h}$ and had their moisture measured by dry to wet weight ratios. Means were compared using Tukey's test at $5 \%$ significance.

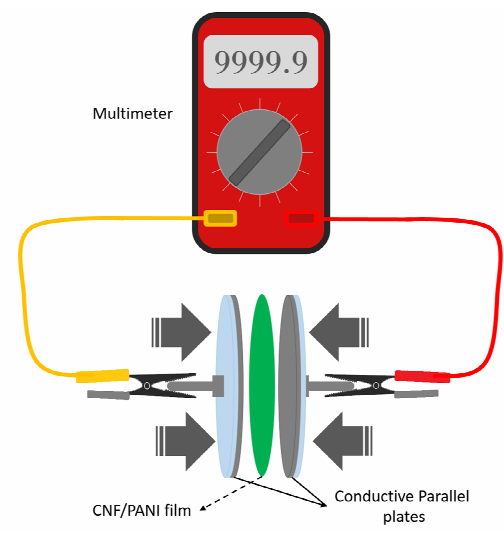

Figure 2: Scheme of the parallel plate apparatus for measurement of the film capacitance

\section{Electrochemical impedance spectroscopy}

The nanocomposite films were analyzed by EIS in order to evaluate their charge transfer resistance capabilities. A PGSTAT30 Autolab electrochemical system (Metrohm) was used. Fluorine-doped tin oxides (FTO) were used as substrate for the deposition of the composite material and set as working electrode. $\mathrm{Ag} / \mathrm{AgCl}\left(3 \mathrm{~mol} \mathrm{~L}^{-1} \mathrm{KCl}\right)$ and platinum lamina were chosen as reference and counter electrodes, respectively. EIS measurements were performed using 0.05 mol. $\mathrm{L}^{-1}\left[\mathrm{Fe}(\mathrm{CN})_{6}\right]^{-3 /-4}$ containing $0.1 \mathrm{~mol} \mathrm{~L}^{-1} \mathrm{KCl}$ at a potential of $0.3 \mathrm{~V}$, varying the frequency from $0.1 \mathrm{~Hz}$ to $100.0 \mathrm{kHz}$, with an amplitude of $10 \mathrm{mV}$. In order to understand the electrical properties and obtain further information about the synergism between the materials, the impedance data were successfully fitted 
with the equivalent circuit, which considered the solid electrolyte interface resistance values $\left(R_{s}\right)$ and charge transfer resistance $\left(\mathrm{R}_{\mathrm{ct}}\right)$.

\section{RESULTS AND DISCUSSION Characteristics of CNF}

The CNF suspension was successfully obtained. The number of passages was based on previous studies ${ }^{35,40,41}$ for successful fibrillation. The suspension passing time increased with the number of passages (Fig. 3). This fact may indicate an increase in fibrillation, which results in a more homogeneous and viscous suspension than the starting pulp. Ioelovich ${ }^{42}$ reported an increase of the internal and external surface area of the fibers, which enhances their capacity to immobilize high amounts of water molecules, endowing a gelled appearance correlated to higher suspension viscosity. The inset in Figure 3 shows individualized nanofibrils. Such an increase in surface area, due to the high aspect ratio fibrils, can enhance mechanical performance, ${ }^{31}$ as well as provide more sites for PANI to attach.

\section{Surface fracture of the films}

The film morphology was investigated by SEM images of the cross-section fracture (Fig. 4), from which it is possible to note the individualization of CNF with fibrillation.

The addition of $\mathrm{HCl}$, during in situ polymerization, showed a harmful effect on the CNF films. The acid used in higher concentrations degraded the amorphous sections of the nanofibrils, causing polysaccharide losses ${ }^{43}$ and consequently a decrease in material properties. It is possible to note that the CNF films with no addition of PANI or any acid presented intact and well-exposed nanofibrils (Fig. 4 (e)), while in the presence of $\mathrm{HCl}$ (Fig. 4 (d and f)), presented burst fibers. However, citric acid (Fig. 4 (c)) seems to be milder in terms of degradation, compared to $\mathrm{HCl}$.

The concentration of the $\mathrm{CNF}$ in the suspension was approximately $0.9 \%(\mathrm{w} / \mathrm{w})$ and the aniline/CNF ratio was up to around $5.3 \%$ $(\mathrm{w} / \mathrm{w})$. However, the complete conversion of aniline to PANI is not common, usually reaching $90 \%$, at most. Even though other authors reported the use of higher concentration of aniline in their cellulose films, ${ }^{15,44}$ the aim of this work was to enhance cellulose properties without being masked by PANI.

Visually, it was not possible to distinguish the presence of PANI on the surface of the nanofibrils and this could be caused by the low amount of aniline used or due to the fact that they are both organic compounds, making it difficult to discriminate between them by image analysis. Silva et $a l .{ }^{37}$ and Gopakumar et al..$^{33}$ showed a softened surface, very similar to that depicted in Figure 4 (d) and reported the roughness of the surface as the visual evidence of successful polymerization of PANI onto CNF. Hu et al. ${ }^{15}$ and Liu et al. $^{44}$ showed that PANI at low concentrations created a film-like coating on the surface of the nanofibrils, forming some clusters, which became more evident with the increase in monomer concentration. The concentration used in the present work was lower than that employed by Silva $e t a l .{ }^{37}$ and $\mathrm{Hu}$ et al., ${ }^{15}$ which makes the PANI structures difficult to be visualized by electron microscopy.

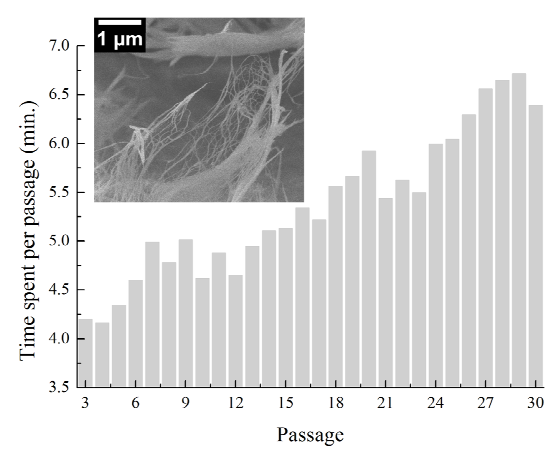

Figure 3: Time spent for each passage of the suspension through the grinder (inset shows a FE-SEM micrograph of a fiber successfully defibrillated into nanofibrils 

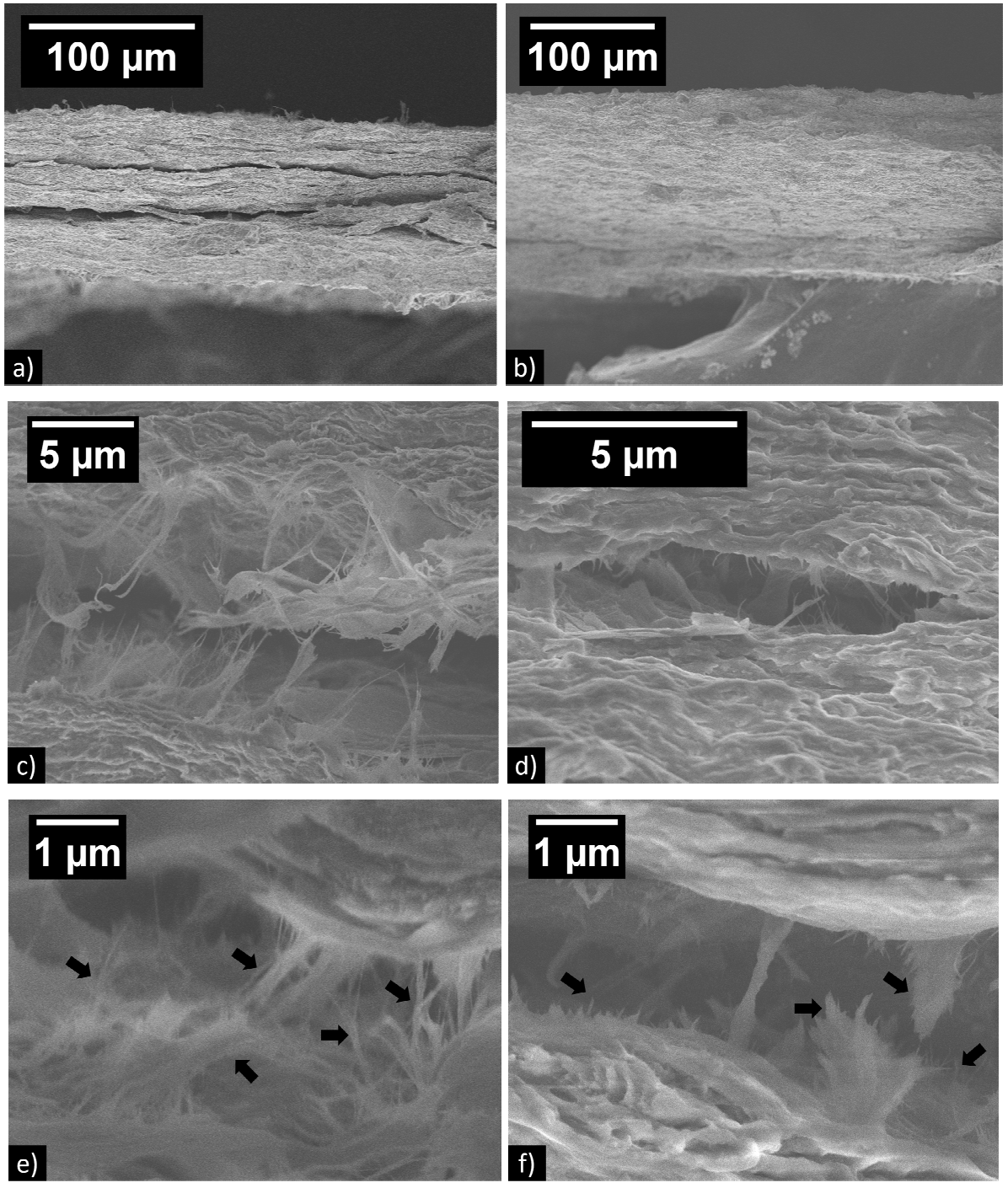

Figure 4: Typical SEM images of PANI and CNF films: a) cross-section of PANI and citric acid film; b) cross-section of PANI and hydrochloric acid film; c) cellulose nanofibrils, PANI and citric acid film; d) cellulose nanofibrils, PANI and $\mathrm{HCl}$ film; e) nanofibrils film with neither PANI nor any acid (arrows show intact nanofibrils); f) nanofibril film with addition of only $\mathrm{HCl}$ (arrows shows bursting of nanofibrils)

The coating of PANI on CNF occurs mainly due to the hydroxyl groups of the latter, causing PANI chains to settle on the surface of the nanofibrils, instead of forming agglomerates. ${ }^{15,44}$ Since PANI in suspension hardly forms an interconnected net, because of its disordered conformation, combining PANI with $\mathrm{CNF}$ provides longer PANI chains and more intensive cross-linking. ${ }^{45}$

\section{FTIR-ATR}

The FTIR spectra of the films are shown in Figure 5. Typical peaks for $\mathrm{C}-\mathrm{C}$ stretching of benzoic and quinoid rings of PANI were found around 1450 and $1550 \mathrm{~cm}^{-1}$, respectively, as reported elsewhere. ${ }^{7,8,32,46,47}$ Citric acid (Fig. 5 (a)) presented a prominent peak at $1729 \mathrm{~cm}^{-1}$ due to $\mathrm{C}=\mathrm{O}$ stretching, ${ }^{49}$ which masked benzoic and quinoid neighboring peaks.

The films doped with higher concentrations of $\mathrm{HCl}(\mathrm{H} 1.0$ and $\mathrm{H} 2.0)$ presented two broad bands at 2887 and $3319 \mathrm{~cm}^{-1}$ (Fig. 5 (b)), corresponding to the vibrations of $\mathrm{H}-\mathrm{Cl}$ of $\mathrm{HCl}$ molecules and stretching $\mathrm{O}-\mathrm{H}$ groups present in water and cellulose molecules, respectively. The $\mathrm{HCl}$ molecules show vibration in the range of 2600 to $3100 \mathrm{~cm}^{-1}$ and when interacting with water, these values change to 2740 to $2840 \mathrm{~cm}^{-1}$. ${ }^{48}$ The increase in intensity may also indicate successful 
doping of PANI, since more $\mathrm{H}^{+}$ions are involved in PANI protonation.

The control film (CNF) presented broad peaks around 3319 and $2887 \mathrm{~cm}^{-1}$ due to water bound $\mathrm{O}-\mathrm{H}$ stretching ${ }^{50}$ and $\mathrm{C}-\mathrm{H}$ stretching, probably referred to the methyl group of cellulose. ${ }^{7,15}$ The peaks in the range of $900-1150 \mathrm{~cm}^{-1}$ refer to vibrations inside the glycosidic ring of cellulose, mainly $\mathrm{C}-\mathrm{C}$ and $\mathrm{C}-\mathrm{O}$ deformations. ${ }^{10}$

Higher intensity of high-frequency broad peaks $\left(>2600 \mathrm{~cm}^{-1}\right)$ of $\mathrm{O}-\mathrm{H}$ and $\mathrm{C}-\mathrm{H}$ stretching could indicate weakening in intermolecular binding, which becomes more accessible to PANI grafting onto cellulose ${ }^{8}$ in the films with higher concentration (H1.0 and $\mathrm{H} 2.0$ ).

\section{Color spectroscopy analysis}

The basic parameters of the technique $\left(\mathrm{L}^{*}, \mathrm{a}^{*}\right.$ and $\left.b^{*}\right)$ were determined. The red-green $\left(a^{*}\right)$ coordinate axis presented groups with distinct values (Fig. 6 (a)). The films produced with only CNF presented lower absolute green values, followed by the films with PANI doped with citric acid. Higher absolute values of green were observed for the films with $\mathrm{HCl}$ doped PANI (greener samples), which indicates the formation of emeraldine salt. ${ }^{20,51}$ The $a^{*}$ values were expected for the films with PANI, which indicates PANI polymerization and doping were both successful. This fact can be related to the improved PANI doping by the acids, once stronger acids produce more protonic hydrogen with high degrees of ionization. ${ }^{44}$

The calculation of the total color difference $(\Delta \mathrm{E})$ (Fig. 6 (b)) showed that all the films containing PANI presented similar values, which were very different from the control CNF films (Fig. 6 (c)). Color spectrometry corroborates with FTIR analysis, indicating that the polymerization of PANI onto CNF was successful for both acids.
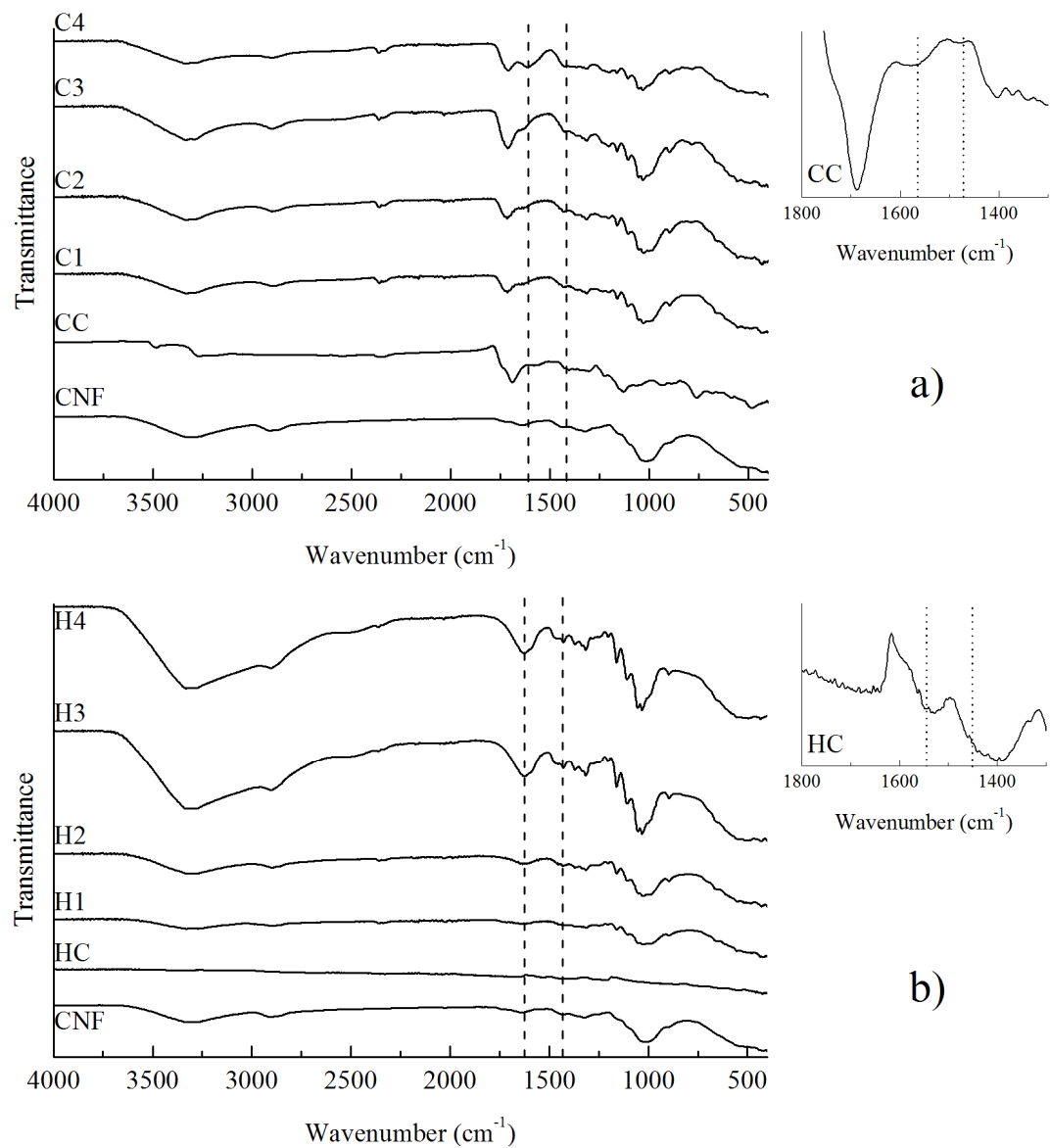

Figure 5: FTIR spectra of films doped with different acids and concentrations: a) films produced with PANI doped with citric acid; b) films produced with PANI doped with $\mathrm{HCl} ; \mathrm{CC}=$ citric acid control; $\mathrm{HC}=$ hydrochloric acid control 


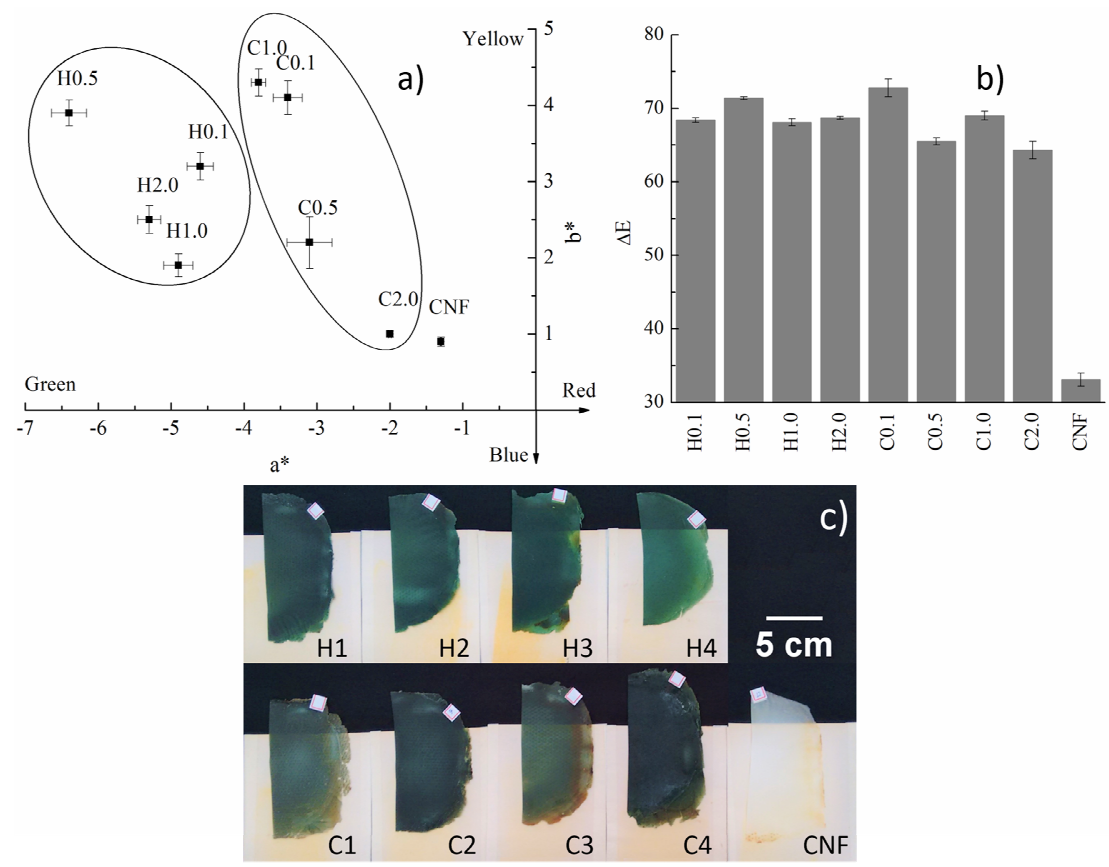

Figure 6: Color spectrometry analysis: a) mean and standard deviation values of $a^{*}-b^{*}$ coordinates (lower values of $a^{*}$ indicate specimens having greener shade than red, while higher values of $b^{*}$ indicate films tending to present more yellow than blue color); b) mean and standard deviation values of total color difference $(\Delta \mathrm{E})$; $\mathrm{c})$ optical images of the films

\section{Parallel plate capacitance}

Parallel plate capacitance measurements are shown in Table 2. These values are consistent with literature and may differ because of the experimental apparatus. A dielectric constant value not greater than 7 is frequently reported for cellulose fibers and nanofibers. ${ }^{4,5}$

Table 2

Mean and standard deviation values of dielectric constant $(\mathrm{k})$ of films submitted to drying and room conditions

\begin{tabular}{lcccc}
\hline \multicolumn{5}{c}{$\mathrm{k}$} \\
\hline Film & Dry & $\begin{array}{c}\text { Environmentally } \\
\text { conditioned }\end{array}$ & $\begin{array}{c}\text { Room-conditioned } \\
\text { moisture }(\%)\end{array}$ & $\mathrm{k}_{\text {room }} / \mathrm{k}_{\text {dry }}$ \\
\hline $\mathrm{H} 0.1$ & $1.2 \pm 0.1^{\mathrm{e}}$ & $2.7 \pm 0.2^{\mathrm{c}}$ & 4.4 & 2.1 \\
$\mathrm{H} 0.5$ & $1.2 \pm 0.1^{\mathrm{e}}$ & $11.7 \pm 1.3^{\mathrm{c}}$ & 4.7 & 9.6 \\
$\mathrm{H} 1.0$ & $4.1 \pm 0.4^{\mathrm{b}}$ & $2551.2 \pm 213.8^{\mathrm{a}}$ & 8.5 & 620.7 \\
$\mathrm{H} 2.0$ & $6.8 \pm 0.5^{\mathrm{a}}$ & $979.2 \pm 69.1^{\mathrm{b}}$ & 10.5 & 145.1 \\
$\mathrm{C} 0.1$ & $1.5 \pm 0.2^{\mathrm{d}}$ & $2.5 \pm 0.2^{\mathrm{c}}$ & 4.7 & 1.7 \\
$\mathrm{C} 0.5$ & $0.7 \pm 0.0^{\mathrm{f}}$ & $1.1 \pm 0.1^{\mathrm{c}}$ & 6.7 & 1.6 \\
$\mathrm{C} 1.0$ & $1.8 \pm 0.0^{\mathrm{c}}$ & $2.8 \pm 0.2^{\mathrm{c}}$ & 8.7 & 1.5 \\
$\mathrm{C} 2.0$ & $1.8 \pm 0.0^{\mathrm{c}}$ & $2.5 \pm 0.2^{\mathrm{c}}$ & 7.0 & 1.4 \\
$\mathrm{CNF}$ & $0.4 \pm 0.0^{\mathrm{g}}$ & $0.8 \pm 0.0^{\mathrm{c}}$ & 5.2 & 1.8 \\
\hline
\end{tabular}

$\mathrm{k}_{\mathrm{dry}}=$ dielectric constant of oven-dried films; $\mathrm{k}_{\text {room }}=$ dielectric constant of films under room conditions;

Means followed by the same letter did not differ at $5 \%$ significance

Higher values of $\mathrm{k}$ were observed for the film H1.0, which increased up to 620 times when the film presented $8.5 \%$ of moisture. Higher dielectric constants allow high capacitance in a thicker and high current leakage material. Thus, high-k films are interesting to produce low-temperature thin film capacitors. ${ }^{52}$ The films doped with higher concentrations of $\mathrm{HCl}$ yielded significantly higher 
values than the other treatments, in both conditions. This may be related to the increased doping and the more hydrophilic character of those films with high $\mathrm{HCl}$ concentration. This was shown in FTIR analysis (broader peaks in 4000$2600 \mathrm{~cm}^{-1}$ range), raising capacitance with the aid of water molecules in the nanostructured films.

Barra et ll $^{39}$ investigated the variation of the capacitance of $\mathrm{CNF}$ with their exposure to moisture saturated environment, and achieved capacitance values up to three-fold those of the dry nanofibers. CNF presents a large surface area and consequently high hydrophilicity created by more hydroxyl groups being exposed. Chani et $a l .{ }^{13}$ obtained capacitance for cellulosic films reaching up to 127 times with increasing humidity. The high hydrophilicity of cellulose promotes the adsorption/absorption of water, which contributes to charge transport within the films, improving its capacitive character. According to Pereira et al., ${ }^{3}$ the water contained in the films dissociated in $\mathrm{H}^{+}$and $\mathrm{OH}^{-}$ions, led to the creation of an electric double-layer that greatly increased the capacitance at low frequencies.

$\mathrm{H} 1.0$ and $\mathrm{H} 2.0$ presented higher values of $\mathrm{k}$ than other films, regardless of moisture. All the other films did not differ statistically when roomconditioned. However, the dried films of all the composites with PANI presented higher values than CNF only. This fact emphasizes the high capacitive characteristics of the films modified with PANI, showing its considerable gain in modifying CNF.

It is important to note that capacitance varies depending on the frequency because of different polarization mechanisms. At low frequencies, material charging is attributed to electrode polarization similar to electric double-layer capacitors, reaching higher capacitance values. ${ }^{2,3}$ The present work carried out measurements only at $800 \mathrm{~Hz}$ frequency.

The wide change of the capacitance values for H1.0 and H2.0 films may be an advantage for capacitive humidity sensors, once the dielectric constant values of those films increased with adsorbed/absorbed water.

\section{EIS}

The films were evaluated by EIS and the Nyquist plots are presented in Figure 7. It is possible to observe a semicircular region at high frequencies, which is related to an interfacial charge transfer process and a linear region at low frequencies, corresponding to diffusion processes. $^{51,53-55}$ Marins et al. $^{56}$ fabricated bacterial cellulose films and PANI doped with dodecylbenzene sulfonic acid and found only a semicircle in the Nyquist plots, which, according to the authors, is an expected feature for materials with only one phase. This fact corroborates with the morphological analysis, indicating a good dispersion of PANI throughout the film.

The impedance data have two components: real and complex parts (Z' and Z', respectively), and this makes possible to infer about its electrical properties, ${ }^{53}$ once the real part is related to the resistivity and the complex part is related to the capacitive characters of the material.

The films did not adhere onto the FTO substrate, presenting a self-supporting feature, which made their deposition onto the substrate incomplete. With inadequate deposition, the graphs presented a very similar character to that of the substrate, indicating that the measured properties were highly influenced by the characteristics of FTO. Further studies are still required to improve the deposition of $\mathrm{CNF}$ and PANI films on the substrates used for EIS.

The CNF films presented the most resistive profile of the analyzed materials, as expected, due to the known insulating character of the cellulose. Solid electrolyte interface and charge transfer resistances are shown in Table 3 . The $R_{s}$ of all the films were similar to FTO, because the interface was poorly established, and the features of the substrate were strongly represented for all the samples investigated. However, $\mathrm{R}_{\mathrm{ct}}$ was positively affected by the presence of PANI in the films. It may be noted that all the films containing PANI showed a lower $\mathrm{R}_{\mathrm{ct}}$ than pure cellulose. The low charge transfer resistance may have assisted the dielectric constant gain reported by the parallel plate measurements.

Although PANI may boost resistance with increasing moisture ${ }^{57}$ the behavior of cellulose in lowering resistivity ${ }^{13}$ in the presence of water may prevail in relation to PANI due to the higher proportion of cellulose in the film.

A decrease in $\mathrm{R}_{\mathrm{ct}}$ is often reported for PANImodified films. Fu et al ${ }^{7}$ observed a decrease of up to one order of magnitude in $\mathrm{R}_{\mathrm{ct}}$ when PANI was added to the films. The authors attributed the decrease in resistivity to the easy diffusion of the electrolyte through the material because the high surface area of the films composed of carboxymethylcellulose, CNF and PANI. Yang and $\mathrm{Li}^{25}$ reported a 3 times lower resistance of 


\section{LUIZ EDUARDO SILVA et al.}

CNF films and carbon nanotubes when PANI was added.
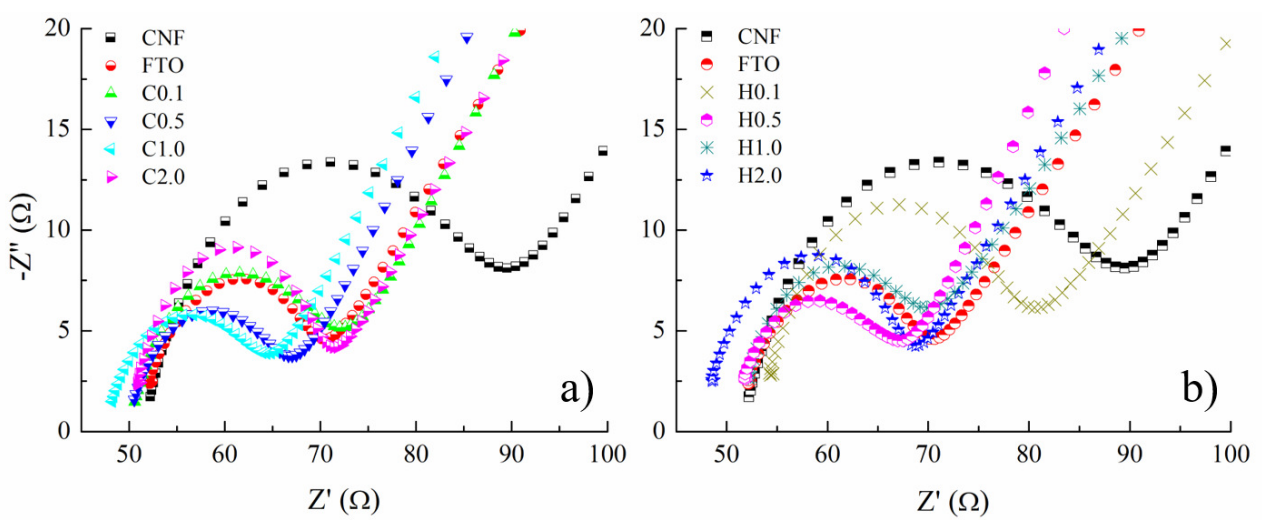

Figure 7: Typical Nyquist plots for: a) net FTO, FTO modified with CNF films and CNF with PANI doped with citric acid; b) net FTO, and FTO modified with CNF films, and CNF with PANI doped with $\mathrm{HCl}$

Table 3

Means values of resistances obtained from equivalent circuits

\begin{tabular}{lcc}
\hline \multirow{2}{*}{ Film } & \multicolumn{2}{c}{ Resistance $(\Omega)$} \\
\cline { 2 - 3 } & $\begin{array}{c}\text { Solid electrolyte } \\
\text { interface }\left(\mathrm{R}_{\mathrm{s}}\right)\end{array}$ & $\begin{array}{c}\text { Charge transfer } \\
\left(\mathrm{R}_{\mathrm{ct}}\right)\end{array}$ \\
\hline $\mathrm{H} 0.1$ & 52.9 & 28.2 \\
$\mathrm{H} 0.5$ & 49.4 & 19.9 \\
$\mathrm{H} 1.0$ & 52.6 & 17.9 \\
$\mathrm{H} 2.0$ & 47.3 & 21.5 \\
C0.1 & 49.9 & 21.2 \\
C0.5 & 49.8 & 16.3 \\
C1.0 & 47.4 & 16.5 \\
C2.0 & 48.9 & 21.6 \\
CNF & 51.5 & 36.1 \\
\hline FTO & 50.3 & 21.9 \\
\hline
\end{tabular}

\section{CONCLUSION}

Composite films of CNF and PANI were successfully produced, where PANI presented a homogenous distribution, coating $\mathrm{CNF}$ as a thin layer, without presenting separated clusters. Burst and degradation of CNF occurred in the presence of hydrochloric acid, whilst citric acid exerted a mild action on the samples. FTIR spectra showed successful polymerization of PANI onto CNF, which was corroborated with color spectrometry. There was no significant color difference between $\mathrm{HCl}$ and $\mathrm{CA}$ films. Capacitance assessed by parallel plate apparatus showed great sensibility to the moisture content in the films. Even though the $\mathrm{HCl}$ doped films presented a higher difference between dry and moist films, the CA films presented an enhancement in their capacitance, even for lower concentrations of acid. The films presented a self-supporting feature, which lowered the contact with the FTO substrate. All of the films with PANI, regardless of the dopant, presented lower charge transfer resistance, which may be important for capacitive applications. Citric acid was demonstrated to be a successful dopant of PANI for composites with CNF and can be used as a substitute for strong acids in green electronics. However, more research is needed in order to enhance its electrical properties.

ACKNOWLEDGMENTS: The authors acknowledge the support of the Fundação de Amparo à Pesquisa do Estado de Minas Gerais FAPEMIG, Coordenação de Aperfeiçoamento de Pessoa de Nível Superior - CAPES, Conselho Nacional de Desenvolvimento Científico e Tecnológico - CNPq, Embrapa Instrumentação, Brazilian Research Network in Lignocellulosic Composites and Nanocomposites - RELIGAR, Brazil, FAPESP (Grant number: 2017/12174-4), MCTI-SisNano (CNPq/402.287/2013-4) and Rede Agronano (EMBRAPA). 


\section{REFERENCES}

X. Wu, C. Lu, H. Xu, X. Zhang and Z. Zhou, ACS Appl. Mater. Inter., 6, 21078 (2014), https://doi.org/10.1021/am505924z

2 D. Gaspar, S. N. Fernandes, A. G. de Oliveira, J. G. Fernandes, P. Grey et al., Nanotechnology, 25, 094008 (2014), 4484/25/9/094008

3 L. Pereira, D. Gaspar, D. Guerin, A. Delattre, E. Fortunato et al., Nanotechnology, 25, 094007 (2014), https://doi.org/10.1088/0957-4484/25/9/094007

4 T. Inui, H. Koga, M. Nogi, N. Komoda and K. Suganuma, in Procs. IEEE-Nano, Greece, July 7-10, 2014 ,

pp.

$470-473$ https://doi.org/10.1109/NANO.2014.6967965

A. Petritz, A. Wolfberger, A. Fian, M. IrimiaVladu, A. Haase et al., Appl. Phys. Lett., 103, 153303 (2013), https://doi.org/10.1063/1.4824701

6 X. Zeng, L. Deng, Y. Yao, R. Sun, J. Xu et al., J. Mater. Chem. C, 4, $6037 \quad$ (2016), https://doi.org/10.1039/c6tc01501h

7 J. Fu, Z. Pang, J. Yang, F. Huang, Y. Cai et al., Appl. Surf. Sci., 349, $35 \quad$ (2015), https://doi.org/10.1016/j.apsusc.2015.04.215

8 W. He, X. Zhang, C. Yu, D. Huang and Y. Li, BioResources, $\quad 10, \quad 2969 \quad$ (2015), https://doi.org/10.15376/biores.10.2.2969-2981

9 X. Liu, W. Zhou, X. Qian, J. Shen and X. An,

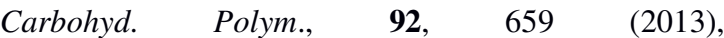
https://doi.org/10.1016/j.carbpol.2012.09.083

10 N. D. Luong, J. T. Korhonen, A. J. Soininen, J. Ruokolainen, L. Johansson et al., Eur. Polym. J., 49, 335

(2013),

https://doi.org/10.1016/j.eurpolymj.2012.10.026

11 D. Correa, E. Medeiros, J. Oliveira, L. Paterno and L. H. Mattoso, J. Nanosci. Nanotechn., 14, 6509 (2014), https://doi.org/10.1166/jnn.2014.9362

12 S. Sinha, S. Bhadra and D. Khastgir, J. Appl. Polym. Sci., 112, $3135 \quad$ (2009), https://doi.org/10.1002/app.29708

13 M. T. S. Chani, K. S. Karimov, S. B. Khan and A. M. Asiri, Sensor. Actuat. A-Phys., 246, 58 (2016), https://doi.org/10.1016/j.sna.2016.05.016

14 Z. A. Boeva and V. G. Sergeyev, Polym. Sci. Ser. C+, $\quad \mathbf{5 6}, \quad 144 \quad$ (2014), https://doi.org/10.1134/S1811238214010032

15 W. Hu, S. Chen, Z. Yang, L. Liu and H. Wang, J. Phys. Chem. B, 115, 8453 (2011), https://doi.org/10.1021/jp204422v

16 P. Cuadro, T. Belt, K. S. Kontturi, M. Reza, E. Kontturi et al., React. Funct. Polym., 90, 21 (2015), https://doi.org/10.1016/j.reactfunctpolym.2015.03.007

17 M. Toivakka, J. Peltonen and R. Österbacka, in "Green Materials for Electronics", edited by M. IrimiaVladu, E. D. Glowacki, N. S. Sariciftci and S. Bauer, Wiley Edition, Vol. 1, 2017, pp. 163-189, https://doi.org/10.1002/9783527692958
18 H. Hussin, S. N. Gan, S. Mohamad and S. W. Phang, Polym. Polym. Compos., 25, 515 (2017), https://doi.org/10.1177/096739111702500702

19 S. Bhadra, D. Khastgir, N. K. Singha and J. H. Lee, Prog. Polym. Sci., 34, 783 (2009), https://doi.org/10.1016/j.progpolymsci.2009.04.003

20 L. Mattoso, E. Medeiros, D. Baker, J. Avloni, D. Wood et al., J. Nanosci. Nanotechn., 9, 2917 (2009), https://doi.org/10.1166/jnn.2009.dk24

21 T. Liu, L. Finn, M. Yu, H. Wang, T. Zhai et al., Nano. Lett., 14, $2522 \quad$ (2014), https://doi.org/10.1021/nl500255v

22 X. Shi, Y. Hu, M. Li, Y. Y. Duan, Y. Wang et al., Cellulose, 21, 2337 (2014) https://doi.org/10.1007/s10570-014-0288-1

23 H. Luo, J. Dong, Y. Zhang, G. Li, R. Guo et al., Chem. Eng. J., 334, $1148 \quad$ (2018), https://doi.org/10.1016/j.cej.2017.11.065

${ }^{24}$ K. Devarayan, D. Lei, H.-Y. Kim and B.-S. Kim, Chem. Eng. J., 273, 603 (2015), https://doi.org/10.1016/j.cej.2015.03.115

25 C. Yang and D. Li, Mater. Lett., 155, 78 (2015), https://doi.org/10.1016/j.matlet.2015.04.096

26 A. Jasim, M. W. Ullah, Z. Shi, X. Lin and G. Yang, Carbohyd. Polym., 163, 62 (2017), https://doi.org/10.1016/j.carbpol.2017.01.056

27 J. Tian, D. Peng, X. Wu, W. Li, H. Deng et al., Carbohyd. Polym., 156, $19 \quad$ (2017), https://doi.org/10.1016/j.carbpol.2016.09.005

28 R. D. S. Oliveira, M. A. Bizeto and F. F. Camilo, Carbohyd. Polym., 199, $84 \quad$ (2018), https://doi.org/10.1016/j.carbpol.2018.06.049

29 D. Müller, J. Mandelli, J. Marins, B. Soares, L. Porto et al., Cellulose, 19, 1645 (2012), https://doi.org/10.1007/s10570-012-9754-9

30 F. V. A. Dutra, B. C. Pires, T. A. Nascimento and K. B. Borges, J. Environ. Manag., 221, 28 (2018), https://doi.org/10.1016/j.jenvman.2018.05.051

31 M. Pääkkö, M. Ankerfors, H. Kosonen, A. Nykänen, S. Ahola et al., Biomacromolecules, 8, 1934 (2007), https://doi.org/10.1021/bm061215p

32 A. Razaq, M. Asif, R. Kalsoom, A. F. Khan, M. Awan et al., J. Appl. Polym. Sci., 132, 42293 (2015), https://doi.org/10.1002/app.42293

33 D. A. Gopakumar, A. R. Pai, Y. B. Pottathara, D. Pasquini, L. C. Morais et al., ACS Appl. Mater. Inter., 10, 20032

(2018), https://doi.org/10.1021/acsami.8b04549

34 M. K. Debnath, M. A. Rahman, K. Tauer, H. Minami, M. M. Rahman et al., Polym. Compos., 39, 4628 (2017), https://doi.org/10.1002/pc.24577

35 M. Guimarães, V. R. Botaro, K. M. Novack, F. Neto, W. Pires et al., J. Nanosci. Nanotechn., 15, 6751 (2015), https://doi.org/10.1166/jnn.2015.10854

36 L. Bufalino, L. M. Mendes, G. H. D. Tonoli, A. Rodrigues, A. S. Fonseca et al., IOP Conf. Ser.-Mat. Sci., 64, 012012 (2014), https://doi.org/10.1088/1757899X/64/1/012012 


\section{LUIZ EDUARDO SILVA et al.}

37 M. Silva, A. Sanches, E. Medeiros, L. Mattoso, C. McMahan et al., J. Therm. Anal. Calorim., 117, 387 (2014), https://doi.org/10.1007/s10973-014-3719-1

38 Hunterlab Applications Note, in Vol. 9, No. 8 "Insight on Color", Hunterlab, 1996, pp. 1-4, http://www.hunterlab.com

39 B. Barra, S. Santos, P. Bergo, C. Alves Jr., K. Ghavami et al., Ind. Crop. Prod., 77, 691 (2015), https://doi.org/10.1016/j.indcrop.2015.07.052

40 C. S. Fonseca, T. F. Silva, M. F. Silva, I. R. C. Oliveira, R. F. Mendes et al., Cerne, 22, 59 (2016), http://dx.doi.org/10.1590/01047760201622012084

${ }^{41}$ L. Bufalino, in "Filmes de Nanocelulose a Partir de Resíduos Madereiros da Amazônia", Federal University of Lavras, 2014, http://repositorio.ufla.br/jspui/handle/1/2405

${ }^{42}$ M. Ioelovich, BioResources, 3, 1403 (2008), http://ncsu.edu/bioresources

43 C. A. Hill, in "Wood Modification: Chemical, Thermal and Other Processes", John Wiley \& Sons, 2007, pp. 260, https://doi.org/10.1002/0470021748

44 S. Liu, T. Yu, Y. Wu, W. Li and B. Li, RSC Adv., 4, 34134 (2014), https://doi.org/10.1039/C4RA07017H

45 H. Yu, P. Chen, W. Chen and Y. Liu, Cellulose, 21, 1757 (2014), https://doi.org/10.1007/s10570-0140189-3

46 H. Mao, X. Liu, X. Qian and X. An, Cellulose, 22, 2641 (2015), https://doi.org/10.1007/s10570-0150689-9

47 T. Omura, C. H. Chan, M. Wakisaka and H. Nishida, ACS Omega, 4, $9446 \quad$ (2019), https://doi.org/10.1021/acsomega.9b00708

48 P. Zemek, J. Van Gompel and S. Plowman, in "Ppm-Level $\mathrm{HCl}$ Measurements from Cement Kilns and Waste Incinerators by FTIR Spectroscopy", MIDAC Corporation, 2012, pp. 10, http://www.midac.com/files/AP-212.pdf
49 N. T. Thuy and D. L. Minh, Adv. Mater. Sci. Eng., 2012, 380306 http://dx.doi.org/10.1155/2012/380306

50 M. J. Silva, A. O. Sanches, L. F. Malmonge, E. S. Medeiros, M. F. Rosa et al., Macromol. Symp., 319, 196 (2012), https://doi.org/10.1002/masy.201100156

51 K. Sharma, K. Pareek, R. Rohan and P. Kumar, Int. J. Energ. Res., 43, $604 \quad$ (2019), https://doi.org/10.1002/er.4277

52 P. Barquinha, R. Martins, L. Pereira and E. Fortunato, in "Transparent Oxide Electronics: from Materials to Devices", John Wiley \& Sons, 2012, pp. 312, https://doi.org/10.1002/9781119966999

53 F. L. Migliorini, R. C. Sanfelice, L. A. Mercante, R. S. Andre, L. H. Mattoso et al., Appl. Surf. Sci., 443, 18 (2018),

https://doi.org/10.1016/j.apsusc.2018.02.168

54 J. Jiang and X. Du, Nanoscale, 6, 11303 (2014), https://doi.org/10.1039/c4nr01774a

55 Q. Wang, J.-E. Moser and M. Grätzel, J. Phys. Chem. B, 109, $14945 \quad$ (2005), https://doi.org/10.1021/jp052768h

56 J. A. Marins, B. G. Soares, M. Fraga, D. Müller and G. M. Barra, Cellulose, 21, 1409 (2014), https://doi.org/10.1007/s10570-014-0191-9

57 K. Sajjan, A. S. Roy, A. Parveen and S. Khasim, J. Mater. Sci.-Mater. El., 25, 1237 (2014), https://doi.org/10.1007/s10854-014-1715-7 